\title{
A DOUBLE-BLIND RANDOMIZED CONTROLLED TRIAL OF LOW DOSES OF PROPRANOLOL, NORTRIPTYLINE, AND THE COMBINATION OF PROPRANOLOL AND NORTRIPTYLINE FOR THE PREVENTIVE TREATMENT OF MIGRAINE
}

\author{
Renan B. Domingues ${ }^{1,2}$, André L. Pirajá da Silva', Simone A. Domingues?', \\ Camila Catherine H. Aquino', Gustavo W. Kuster
}

\begin{abstract}
Few trials have evaluated combination of two or more drugs in the preventive treatment of migraine. In this study three therapeutic regimens were compared: (a) propranolol, at a dose of $40 \mathrm{mg}$ per day, (b) nortriptyline, at a dose of $20 \mathrm{mg}$ per day, and (c) the combination of these two drugs in these dosages. The groups were matched according to age, gender, and frequency of migraine attacks prior to treatment. The period of treatment was two months and the frequency and intensity of headache attacks of the 30 days pretreatment period were compared with the frequency of headaches in the treatment period. Fourteen patients in groups $A$ and $B$ and sixteen patients in group $C$ have completed the study. Treatment with propranolol, alone or in combination, was shown to be effective. Treatment with nortriptyline alone was not effective. All three therapeutic regimens were safe and side effects were minimal. The frequency of discontinuation of the study was the same in the 3 groups but no patient left the study due to adverse reactions. The combined therapy proved to be as safe as the monotherapy. Further studies evaluating this and other possible combinations of drugs in higher doses and for longer periods, should more clearly elucidate the role of combined therapy in the treatment of migraine.
\end{abstract}

KEY WORDS: combined therapy, migraine, nortryptiline, propranolol.

Estudo controlado, randomizado e duplo cego do uso de baixas doses de propranolol, nortriptilina e a combinação destas duas drogas no tratamento preventivo da migrânea

Resumo - Poucos ensaios clínicos têm avaliado o tratamento preventivo da migrânea através da combinação de drogas. Neste estudo, três regimes terapêuticos foram comparados: (a) popranolol, na dose de $40 \mathrm{mg}$ por dia, (b) nortriptilina, na dose de 20 mg por dia e (c) combinação destas duas drogas nestas dosagens. Os grupos foram pareados de acordo com idade, sexo e freqüência de crises previamente ao tratamento. O período de tratamento foi de dois meses e a frequência e a intensidade das crises de cefaléia do período pré-tratamento foram comparadas com as do período de tratamento. Concluíram o estudo 14 pacientes do grupo A, 14 do grupo B e 16 do grupo C. Os tratamentos com propranolol, isolado ou em associação mostraram-se eficazes. O tratamento com nortriptilina isolada não se mostrou eficaz para a redução do número de dias com cefaléia. Todos os três regimes terapêuticos foram seguros e os efeitos colaterais foram mínimos. A freqüência de abandono do estudo foi a mesma nos 3 grupos e nenhum paciente abandonou o estudo devido a reações adversas. A terapia combinada mostrou-se tão segura quanto a monoterapia. Estudos futuros avaliando esta e outras possíveis combinações de drogas, em doses maiores e por períodos mais longos, deverão elucidar mais claramente o papel da terapia combinada no tratamento da migrânea.

PALAVRAS-CHAVE: migrânea, nortriptilina, propranolol, tratamento combinado.

\footnotetext{
${ }^{1}$ Headache Clinic, Department of Pathology, Escola Superior de Ciências da Saúde de Vitória (EMESCAM), Vitória ES, Brazil; ${ }^{2}$ Neurosciences Postgraduation Program, Federal University of Minas Gerais (UFMG), Belo Horizonte MG, Brazil.
}

Received 25 July 2009. Accepted 3 August 2009.

Dr. Renan Barros Domingues - Av. Nossa Senhora da Penha 699 / 709 - 29055-137 Vitória ES - Brasil. E-mail: renan-domingues@uol.com.br. Home-page: www.renandomingues.med.br 
Migraine is a common and disabling primary headache disorder with worldwide prevalence of $10-12 \%$ of adult population'. In a recent brazilian national survey migraine was detected in $15.2 \%$ of the adult population ${ }^{2}$. There are high impact and costs of migraine in the Brazilian public health system ${ }^{3}$. Prophylactic treatment of migraine is used in order to reduce the frequency of migraine attacks. It can improve the quality of life of the patients ${ }^{4}$ and reduce the burden of migraine ${ }^{3}$.

A variety of drugs from diverse pharmacological classes are in use for migraine prevention ${ }^{5}$. Beta-adrenergic blockers, such as propranolol, are among the most prescribed drugs for migraine prophylaxis ${ }^{6,7}$. There is clear evidence that propranolol is more effective than placebo in the treatment of migraine ${ }^{6}$. The usual propranolol doses for migraine prevention in clinical trials have ranged from 80 to $160 \mathrm{mg}$ a day ${ }^{6-9}$. Antidepressants, especially tricyclic agents such as amitriptyline and nortriptyline, have also been a mainstay in the prophylatic therapy of migraine ${ }^{10}$. Most studies have evaluated the efficacy of such drugs alone; however, there are some studies with propranolol ${ }^{11,12}$ and tricyclic agents ${ }^{13}$ in association with other drugs. The clinical experience with combination therapy for migraine seems to be a rational approach when monotherapy fails and when migraine is refractory ${ }^{14}$. Another potential advantage of the combination therapy is the possibility of using lower doses of the combined agents thus reducing the chance of side effects. However, combination therapy still needs to be better evaluated by controlled clinical trials ${ }^{14}$.

In this study we have evaluated the short term efficacy and safety of the combination of low doses of propranolol and nortriptyline compared to these drugs alone.

\section{METHOD}

The study was conducted at the headache outpatient clinic of EMESCAM and received full approval from the Research Ethics Committee (CEP) of this institution. Patients with clinical diagnosis of migraine and chronic migraine according to International Headache Society criteria of 2004 were selected ${ }^{15}$. The inclusion criteria were: age over 18 years, presence of 4 or more attacks of migraine per month, no prior or current prophylactic treatment for migraine, no clinical conditions that precluded the use of any of the drugs of the study, such as bronchial asthma, symptomatic hypotension, hyperprolactinemia, bladder retention, or known hypersensitivity to any of these drugs.

The patients were randomized into 3 groups according to gender, age, and frequency of crises. The first (group A) received propranolol, the second (group B) received nortriptyline, and the third (group C) received the combination of nortriptyline and propranolol. The doses of propranolol were $20 \mathrm{mg}$ in the first two weeks and $40 \mathrm{mg}$ in the six consecutive weeks, two times a day. The doses of nortriptyline were $10 \mathrm{mg}$ in the first two weeks and $20 \mathrm{mg}$ during the next six weeks, two times a day. The doses of each of these drugs were the same when given alone or in combination. All tablets were handled by the same supplier, a pharmacy certified by NBR ISO 9001:2000. The medications were not identified on the bottle. The identification of the medication was not known by the researcher who was responsible for the clinical assessment of the patients.

The patients were followed for a period of 3 months, during which they were instructed to fill a headache diary with the following information: presence of headache and intensity of headache (0 - no headache, 1 - mild headache, 2 - moderate headache, 3 - severe headache). In the first month, patients have received no prophylactic medication. The patients were instructed to use the medications during the second and the third months of the follow up. After the first visit, which was the initial assessment, signature of a consent form, and guidance on the study procedures, and the instructions about the completion of the headache diary were done. Patients were instructed to return on days 30,45, 60 and 90 . On day 30 the patents began the medication with the initial doses. On day 45 the definitive doses were given and maintained during the next six weeks. The diaries were returned to the research team on days 30,60 and 90 .

The analyses have compared the headache diary of the first 30 days (before start of medication) with the diaries between days 60 and 90 (with full dose of the preventive medication). The primary outcome evaluated was the proportion of patients in each group that achieved a $50 \%$ reduction in the number of days with headache. Secondary outcomes were: reduction of the number of days with headache per month, frequency of side effects, and the proportion of patients abandoning the study before the end of medication. The causes of noncompliance and side effects were individually registered. We have analyzed the data from the three groups of patients with migraine and the three subgroups of patients fulfilling criteria for the diagnosis of chronic migraine within these groups.

Chi-square test was used for the comparison of the proportions of patients achieving $50 \%$ reduction of headache days in the three groups. The mean headache days and headache indices of the pre-treatment period and the treatment period in each group were compared with $t$ test. The number of headache days and headache indices were compared between the three different groups with Wilcoxon matched pair test. The level of significance was set at $\mathrm{p}<0.05$.

\section{RESULTS}

Seventy-six patients entered the study, with 25 in group A, 24 in group B and 27 in group C. There were no significant differences in age of patients of three groups $(p=0.4)$ and there were no differences in the gender distribution ( $p=0.8)$. Forty-four patients completed the study, fourteen in group $A$, fourteen in group $B$, and sixteen in group $C$. Among patients who completed the study twenty-nine had chronic migraine, nine in group $A$, ten in group 
Table 1. Reasons for exclusion of study.

\begin{tabular}{lccc}
\hline & $\begin{array}{c}\text { Group A } \\
\text { propranolol }\end{array}$ & $\begin{array}{c}\text { Group B } \\
\text { nortriptyline }\end{array}$ & $\begin{array}{c}\text { Group C } \\
\text { propranolol plus nortriptyline }\end{array}$ \\
\hline Loss of the headache diary & 3 & 0 & 3 \\
Patients that did not return in day 30 & 7 & 9 & 6 \\
Inadequate use of the medications & 1 & 0 & 1 \\
Patients desiring to discontinue in day 30 & 0 & 1 & 2 \\
Medication intolerance & 0 & 0 & 0 \\
\hline
\end{tabular}

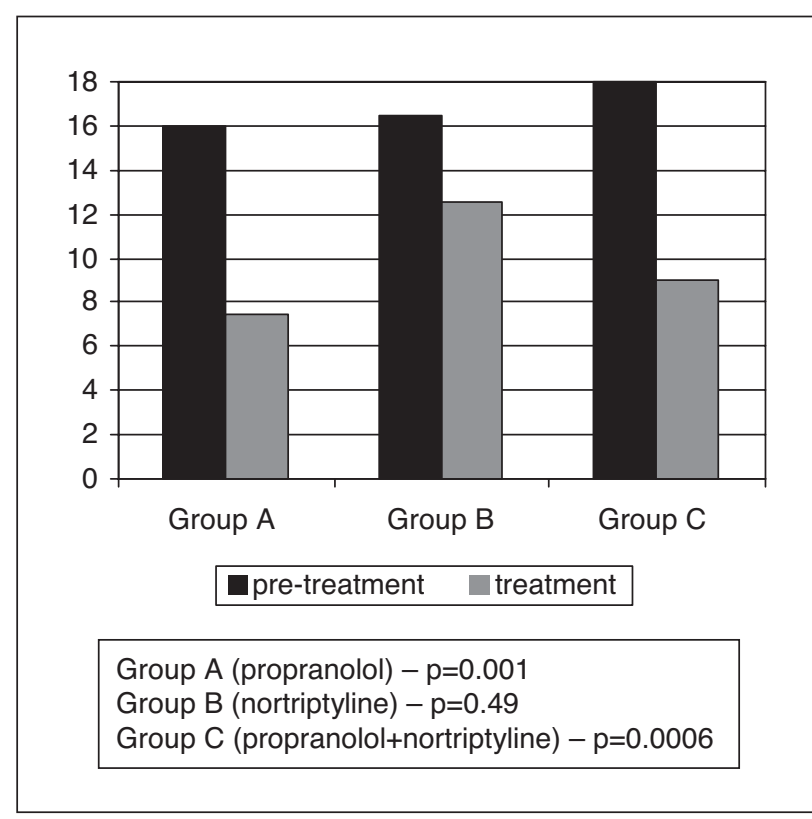

Fig 1. Median headache days in the pre treatment and treatment phases.

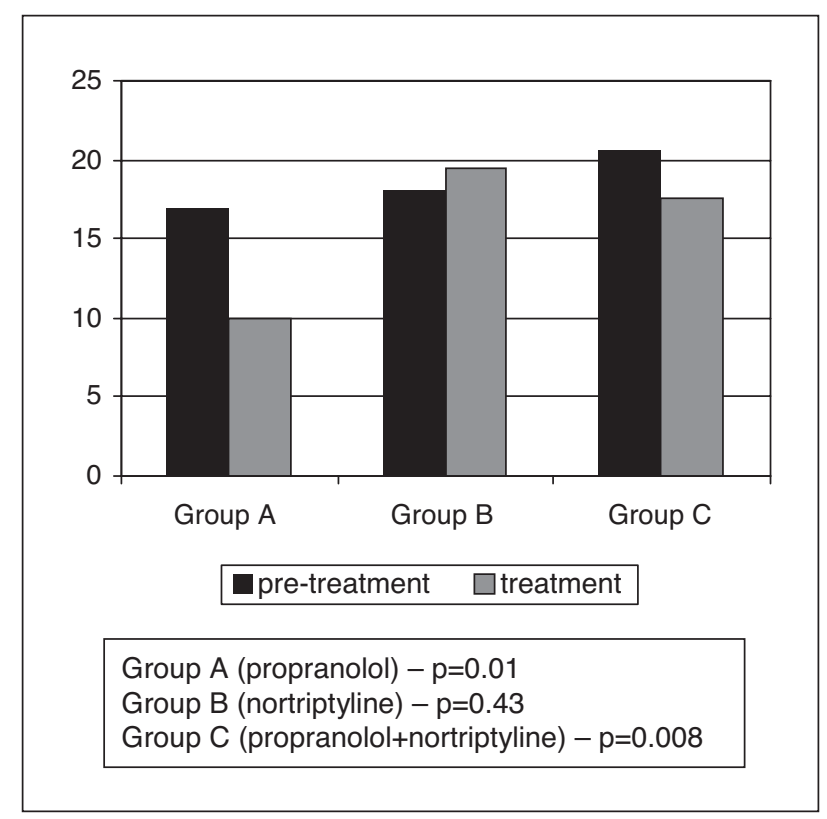

Fig 2. Median headache days in the pre treatment and treatment phases of the three subgroups of patients with chronic migraine.

Table 2. Side effects in the three groups.

\begin{tabular}{lcccc}
\hline & $\begin{array}{c}\text { Group A } \\
\text { propranolol }\end{array}$ & $\begin{array}{c}\text { Group B } \\
\text { nortritptyline }\end{array}$ & propranolol plus nortryptiline & $p^{*}$ \\
\hline Xerostomy & 1 & 5 & 8 & $0.03^{* *}$ \\
Weight gain & 2 & 3 & 8 & 0.07 \\
Somnolence & 1 & 6 & 4 & 0.09 \\
Dizziness & 5 & 2 & 4 & 0.4 \\
Constipation & 1 & 2 & 2 & 0.8 \\
No side effects & 7 & 6 & 6 & 0.78 \\
\hline
\end{tabular}

*According to Chi-square test; **Significant difference.

$B$, and ten in group $C$. The proportion of patients who completed the study did not differ significantly between the 3 groups $(p=0.9)$. The proportion of patients with chronic migraine in the three groups was not significantly different $(p=0.86)$. When comparing the age and gender distribution of patients who completed the study for the three groups and the subgroups of patients with chronic migraine, there were also no significant differences. The causes of the exclusion from the study are listed in Table 1.

The proportions of patients who achieved at least $50 \%$ reduction in the number of days with headache in the 3 groups were: group A $42.8 \%$, group B $28.6 \%$ and group C 
$37.5 \%(p=0.73)$. The analysis of subgroups of patients with chronic migraine also revealed no significant differences between the groups in the reduction greater than or equal to $50 \%$ in the number of days with headache: group A $55.5 \%$, group B $30 \%$, and group C $30 \%(p=0.42)$. When comparing in each group the number of days with headache in the pre treatment phase and the mean number of days with headache in the treatment phase, the difference was significant in group $A(p=0.001)$ and group $C(p=0.0006)$. In group $B$ this difference was not statistically significant $(p=0.49)$ (Fig 1). The comparison of the frequency of headache in the pre and treatment phases of the three subgroups of patients with chronic migraine was significantly different in groups $A$ and $C(p=0.01$ and $p=0.008$, respectively) but it was not significant in group $B(p=0.43)$ (Fig 2). The side effects recorded in the 3 groups are shown in Table 2.

\section{DISCUSSION}

This study found no significantly different results in the proportion of patients achieving a $50 \%$ or more reduction in the frequency of headache days in patients using propranolol, nortryptiline, and the combination of these drugs. The data of patients with chronic migraine were analyzed separately since this condition presents clinical, epidemiological, and therapeutic peculiarities ${ }^{16-18}$. In patients with chronic migraine there was also no superiority of any of these therapeutic regimens when considering the primary endpoint of the study. When comparing the number of days with headache in the period before and during treatment there were differences between these treatments. The propranolol alone has significantly reduced the number of days with headache, both for the whole group as in the subgroup of patients with chronic migraine. The association of propranolol and nortryptiline was also effective in reducing the number of headache days in patients with migraine and patients with chronic migraine. However, the group of patients with migraine and the subgroup of patients with chronic migraine did not have reduction in the number of days with headaches with nortriptyline. There are some possible explanations for these findings. The low efficacy of this drug might be explained by the low dose or the short time used in the present study. Therefore, according to these data, it can not be stated that the combination of drugs does not increase the effectiveness of treatment of migraine and chronic migraine.

None of patients abandoned the study due to side effects of drugs. Propranolol was very well tolerated. The most frequent side effect to this drug, hypotension, was not significantly more frequent than in the other 2 groups. Nortriptyline was also very well tolerated. In groups B and $C$ the frequency of xerostomia was significantly high- er. There was also a higher frequency of weight gain, but it has not reached statistical significance. These findings were already expected considering the profile of side effects of nortriptyline ${ }^{18}$. The combination of drugs did not result in more side effects than monotherapy. This is encouraging in the sense of carrying out further studies of combination of drugs.

This study has several limitations. The number of patients who completed the study in three groups was too small, so that the conclusions on the effectiveness of these treatments must be interpreted very cautiously. In addition, the follow-up time of patients in the therapy phase was only of two months with the first fifteen days for titration of doses. Future studies evaluating the association of drugs in patients with migraine and patients with chronic migraine should include a larger number of patients and should follow patients for at least three months using the drugs. Another limitation is that the symptomatic medications were not registered in the pre treatment and treatment phases. However, despite these limitations, this study points to some data that should be taken into account in future combination drugs studies. First, the use of beta blockers, at doses below those used in previous therapeutic trials that used 80 to $160 \mathrm{mg}$ per day of propranolol $^{9}$, was effective. Therefore low beta blockers doses in combination with antidepressants or other types of drugs may be used in future studies. Second, the combination of these drugs did not result in higher intolerance or more frequent side effects, suggesting that further studies with combination of drugs can be safely carried out.

Pharmacological preventive treatment of migraine and chronic migraine is a major challenge. The use of a single drug has been widely studied, but the combination of drugs could theoretically have advantages, since different substances act on different targets of the pathophysiology of the disease. Although this study has not provided evidence of the therapeutic efficacy of the combined use of nortriptyline and propranolol, the combination of these substances showed to be safe and well tolerated. Further studies using this and other combinations of substances, in larger groups of patients, in higher doses, and for a longer period of time, may help to clarify the role of combined therapy in the treatment of migraine.

AKNOWLEDGEMENTS - The authors gratefully thank the Farmácia Alquimia for the manipulation of the medications used in this study.

\section{REFERENCES}

1. Lipton RB, Stewart WF, Diamond S, et al. Prevalence and burden o migraine in the United States: data from the American Migraine Study II. Headache 2001;41:646-657.

2. Queiroz LP, Peres MFP, Kowacs F, et al. Um estudo epidemiológico nacional da cefaléia no Brasil. Migrâneas Cefaléias 2008;11:190-196.

3. Bigal ME, Rapoport AM, Bordini CA, et al. Burden of migraine in Brazil: 
estimate of cost of migraine to the public health system and an analytical study of the cost-effectiveness of a stratified model of care. Headache 2003;43:742-754

4. Massiou H. Prophylactic treatments of migraine. Rev Neurol (Paris) 2000;156(Suppl 4):S79-S86.

5. Ramadan NM. Current trends in migraine prophylaxis. Headache 2007 47(Suppl 1):S52-S57.

6. Linde K, Rossnagel K. Propranolol for migraine prophylaxis. Cochrane Database Syst Rev 2004:CD003225.

7. Tvedskov JF, Thomsen LL, Thomsen LL, et al. The effect of propranolol on glyceryltrinitrate-induced headache and arterial response. Cephalalgia 2004;24:1076-1087.

8. Pradalier A, Serratrice G, Collard M, et al. Long-acting propranolol in migraine prophylaxis: results of a double-blind, placebo-controlled study. Cephalalgia 1989;9:247-253.

9. al-Qassab HK, Findley LJ. Comparison of propranolol LA $80 \mathrm{mg}$ and propranolol LA $160 \mathrm{mg}$ in migraine prophylaxis: a placebo controlled study. Cephalalgia 1993;13:128-131.

10. Punay NC, Couch JR. Antidepressants in the treatment of migraine headache. Curr Pain Headache Rep 2003;7:51-54.
11. Bordini CA, Arruda MA, Ciciarelli MC, Speciali JG. Propranolol vs flunarizine vs flunarizine plus propranolol in migraine without aura prophylaxis: a double-blind trial. Arq Neuropsiquiatr 1997;55:536-341.

12. Kaniecki RG. A comparison of divalproex with propranolol and placebo for the prophylaxis of migraine without aura. Arch Neurol 1997;54:1141-1145.

13. Keskinbora K, Aydinli I. A double-blind randomized controlled trial of topiramate and amitriptyline either alone or in combination for the prevention of migraine. Clin Neurol Neurosurg 2008;110:979-984.

14. Peterlin BL, Calhoun AH, Siegel S, Mathew NT. Rational combination therapy in refractory migraine. Headache 2008;48:805-819.

15. Headache Classification Subcomitte of the International Headache Society. The Internacional Classification of Headache Disorders. 2nd Edition. Cephalalgia 2004;24:1-160.

16. Bigal ME, Serrano D, Reed M, Lipton RB. Chronic migraine in the population: burden, diagnosis, and satisfaction with treatment. Neurology 2008;71:559-566.

17. Seok JI, Cho HI, Chung CS. From transformed migraine to episodic migraine: reversion factors. Headache 2006;46:1186-1190.

18. Taylor FR. Weight change associated with the use of migraine-preventive medications. Clin Ther 2008;30:1069-1080. 